\title{
Facile and Clean Solution Synthesis of Large-Scale ZnO Nanorods Assisted with Aliquat 336
}

\author{
Qiang Huang ${ }^{1,2}$ and Jianping Liu ${ }^{2}$ \\ ${ }^{1}$ Department of Materials Science and Engineering, Ynnnan University, Kunming, Yunnan 650091, China \\ ${ }^{2}$ Key Laboratory of Medicinal Chemistry for Natural Resource, Ministry of Education, School of Chemical Science and Technology, \\ Yunnan University, Kunming, Yunnan 650091, China
}

Correspondence should be addressed to Qiang Huang; huangqiang@ynu.edu.cn

Received 4 May 2013; Accepted 27 June 2013

Academic Editor: Fernanda Carvalho

Copyright (C) 2013 Q. Huang and J. Liu. This is an open access article distributed under the Creative Commons Attribution License, which permits unrestricted use, distribution, and reproduction in any medium, provided the original work is properly cited.

\begin{abstract}
A facile and clean fabrication of large-scale $\mathrm{ZnO}$ nanorods assisted with Aliquat 336 using aqueous chemical method is reported. As prepared, samples were characterized using XRD, EDS, SEM, TEM, and HRTEM. The optical properties were measured by Raman spectroscopy and room temperature photoluminescence spectra.
\end{abstract}

\section{Introduction}

Zinc oxide $(\mathrm{ZnO})$, a wide band-gap $(3.37 \mathrm{eV})$ II-VI compound semiconductor, has a stable wurtzite structure and large exciton binding energy $(60 \mathrm{meV})$ at room temperature [1]. ZnO nanostructures, especially one-dimensional nano$\mathrm{ZnO}$ such as rods, wires, and tubes, have attracted much attention due to their many unique properties and the possibility that they may be used as building blocks for future electronics and photonics [2-4]. Various chemical, physical, and electrochemical methods, for instance, solidstate routes, hydrothermal reactions, sol-gel, microwave- or ultrasound-assisted synthesis, electrodeposition, and vapor transport process, have been applied for fabrication of 1D $\mathrm{ZnO}$ nanostructures [5-12]. Among these methods, solution chemical route has become a promising option for large-scale production of nanoscale materials because of its simple, fast, less expensive virtues and flexibility of controlling shape and size of the structures by tuning different growth conditions. In solution synthesis of nano- $\mathrm{ZnO}$, an organic additive such as surfactants, soluble polymers, and recent ionic liquids for the control of sizes and morphologies is usually necessary $[13,14]$.

On the other hand, Aliquat 336, a 2:1 mixture of methyl trioctyl ammonium- and methyl tridecyl ammonium chloride (Figure 1) with a proposed mean mole weight of $432 \mathrm{~g} / \mathrm{mol}$, is conventionally employed as a phase-transfer catalyst $[15,16]$, metal extraction reagent [17], and waste water treatment chemical [18]. It presents liquid state at ambient temperatures and is in fact a room temperature ionic liquid (RTIL) or acts as a versatile and affordable cation source for quaternary ammonium ionic liquids $[19,20]$. Moreover, Aliquat 336 is provided with special salts-induced phase behavior [21]. It can be almost completely separated out from aqueous phase and thus be recovered easily. Recently, various RTILs have been used as the solvents, morphology controlled templates, reactants, or so-called all-in-one for fabrication of nanostructured metal oxides because of their negligible vapor pressure, low interfacial energy and tension, ordering of aggregation, high ionic conductivity, and thermostability [22-26]. Although, Aliquat 336 is a conventional and cheap RTIL, there are few reports on using Aliquat 336 for synthesis of inorganic nanomaterials.

In present work, we report a facile synthesis of $\mathrm{ZnO}$ nanorods with Aliquat 336 as a soft template, and the $\mathrm{NaSO}_{4}$ induced recovery of Aliquat 336 is demonstrated.

\section{Experimental}

All reagents employed were commercially available and were directly used without further purification. To obtain $\mathrm{ZnO}$ nanorods, $4.40 \mathrm{~g}(20 \mathrm{mmol}) \mathrm{Zn}\left(\mathrm{CH}_{3} \mathrm{COO}\right)_{2} \cdot 2 \mathrm{H}_{2} \mathrm{O}$ (Sinopharm Chemical Reagent Co., Ltd, 99.5\%) was dissolved 
<smiles>CCCCCCC</smiles>

Methyl trioctylammonium cation

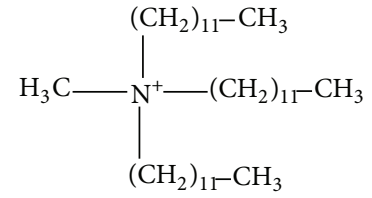

Methyl tridecylammonium cation
Figure 1: The cations of Aliquat 336.

in $50 \mathrm{~mL}$ deionized water and $2.0 \mathrm{~g}(2.3 \mathrm{mmol})$ Aliquat 336 (Aladdin Chemistry Co., Ltd., 98\%) was added to the solution. The mixture was irradiated with ultrasound (SK500LH, Shanghai Kudos, $59 \mathrm{KHz}, 100 \mathrm{~W}$ ) at room temperature for 30 min. Then $\mathrm{NaOH}$ solution $(2 \mathrm{M}, 50 \mathrm{~mL})$ was poured, and the formative white slurry was irradiated with ultrasound for another $15 \mathrm{~min}$. The mixture was stood at $80^{\circ} \mathrm{C}$ for $24 \mathrm{~h}$. The product was separated by centrifugation at $2500 \mathrm{rpm} / \mathrm{min}$ for $20 \mathrm{~min}$. The solid was washed with water and ethanol several times and dried at $60^{\circ} \mathrm{C}$ for $6 \mathrm{~h}$ under vacuum to get the $\mathrm{ZnO}$ nanorod samples. The liquid phase was neutralized with saturated $\mathrm{NaHSO}_{4}$ solution to the $\mathrm{pH}=7.0$. The liquid was irradiated with ultrasound for $30 \mathrm{~min}$ and then was centrifuged for collecting the upper oils.

The X-ray diffraction pattern (XRD) of the product was collected on an RIGAKU D/max-TTR III diffractometer with $\mathrm{Cu}-\mathrm{K} \alpha$ radiation $(\lambda=0.15406 \mathrm{~nm})$. Scanning electron microscopy (SEM) images were obtained on an FEI Quanta 200 equipped with energy dispersive X-ray spectroscopy (EDS). For the measurement, the $\mathrm{ZnO}$ powders were laid on carbon films, and the samples were dried by critical point dryer. Transmission electron microscopy (TEM) and high-resolution transmission electron microscopy (HRTEM) images were taken on a JEM-2100 apparatus with an acceleration voltage of $200 \mathrm{KV}$. The $\mathrm{ZnO}$ sample was redispersed in ethanol, and a drop of this slurry was deposited on a carbon film supported on a copper grid. Photoluminescence (PL) spectra were measured on a Hitachi F-4500 fluorospectrophotometer using a Xe lamp with an excitation wavelength of $325 \mathrm{~nm}$ at room temperature. Raman spectra were recorded by Renishaw inVia microscopic confocal Raman spectrometer system using $514.5 \mathrm{~nm}$ line of an $\mathrm{Ar}^{+}$laser at room temperature in the air operating at $10 \mathrm{~mW}$ laser power.

\section{Results and Discussion}

$\mathrm{ZnO}$ nanorods have grown in an aqueous solution including $\mathrm{Zn}\left(\mathrm{CH}_{3} \mathrm{COO}\right)_{2}$, Aliquat 336, and $\mathrm{NaOH}$. After the formative slurry was pretreated under an ultrasonic water bath, the reaction system was stood under $80^{\circ} \mathrm{C}$ and kept for $24 \mathrm{~h}$. The process is simple and the mass production is easy to achieve. The overall reaction for $\mathrm{ZnO}$ nanostructures in an alkaline solution can be proposed as follows:

$$
\begin{gathered}
\mathrm{Zn}^{2+}+2 \mathrm{OH}^{-} \longrightarrow \mathrm{Zn}(\mathrm{OH})_{2} \\
\mathrm{Zn}(\mathrm{OH})_{2}+2 \mathrm{OH}^{-} \longrightarrow \mathrm{Zn}(\mathrm{OH})_{4}{ }^{2-} \\
\mathrm{Zn}(\mathrm{OH})_{4}{ }^{2-} \longrightarrow \mathrm{ZnO}+2 \mathrm{H}_{2} \mathrm{O}+2 \mathrm{OH}^{-}
\end{gathered}
$$

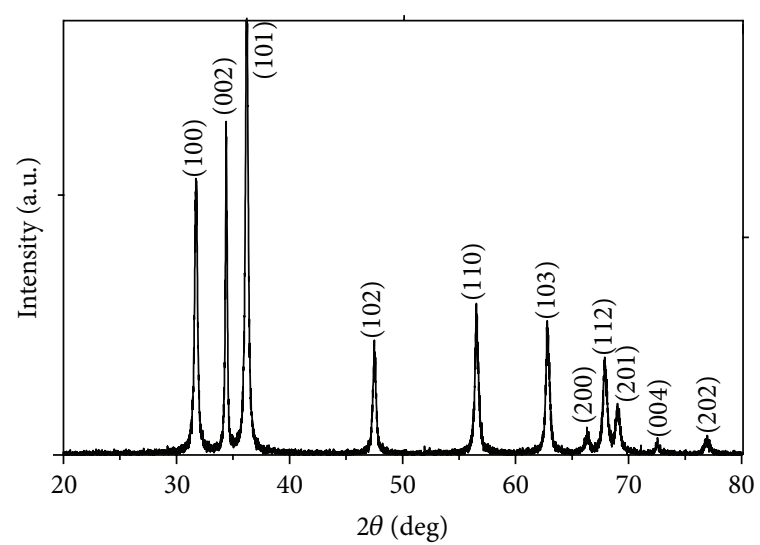

FIGURE 2: A representative XRD pattern of as-prepared $\mathrm{ZnO}$ nanorods.

The growth behavior of crystals is primarily determined by the internal structure of a given crystal and affected by external conditions $[27,28]$. With the presence of Aliquat 336 at high concentration of $\mathrm{OH}^{-}$, the growth habit of $\mathrm{ZnO}$ is restricted to one direction and leads to the formation of $1 \mathrm{D}$ nanorods. The formative mechanism of $\mathrm{ZnO}$ nanorods in current process may be consistent with previous literatures using other cationic surfactants for the synthesis of $\mathrm{ZnO} 1 \mathrm{D}$ nanostructures in alkaline solution, such as CTAB [29-31]. However, it is a significant advantage that Aliquat 336 can be recovered easily after the filtrate was neutralized with saturated $\mathrm{NaHSO}_{4}$ solution and the oil-water phase separation occurred when the filtrate was centrifuged [21]. The average recovery of Aliquat 336 exceeded $90 \%$. No anionic exchange such as $\mathrm{SO}_{4}{ }^{2-}$ and $\mathrm{CH}_{3} \mathrm{COO}^{-}$was detected in the regenerated Aliquat 336.

The powder XRD pattern of as-prepared sample is shown in Figure 2. The diffraction peaks of $\mathrm{ZnO}$ powder coincide with the peaks of $\mathrm{ZnO}$ wurtzite structure with high crystallinity (JCPDF card number 36-1451, space group $\left.P 6_{3} m c\right)$. The calculated lattice constants $(a=0.3252 \mathrm{~nm}$, $c=0.5206 \mathrm{~nm}$ ) are in good agreement with the values in the standard card. No characteristic peaks of other impurities such as $\mathrm{Zn}(\mathrm{OH})_{2}$ are detected in the diffractogram. XRD studies also may suggest strong preferred orientation along the $c$-axis because the (002) reflection is greatly enhanced relative to the standard spectrum of $\mathrm{ZnO}$ powders. The diameters of the samples calculated using Scherrer formula range between about $20 \mathrm{~nm}$ and $80 \mathrm{~nm}$.

The morphology of the as-obtained products was investigated using SEM and TEM. Typical SEM and TEM images are shown in Figure 3. It reveals that the products with rod-like shapes are successfully fabricated under simple processing. The SEM and TEM images show as-obtained nanorods with diameters ranging from 20 to $80 \mathrm{~nm}$ and length from $400 \mathrm{~nm}$ to $1.2 \mu \mathrm{m}$ which also corresponds to their diameters calculated by Scherrer formula according to XRD analysis. In addition, the obtained rod-like crystals are widespread over the whole sample stand, shown in the large-scale SEM at low magnifications in Figure 3(a). These images imply that 
TABLE 1: The wave numbers (in $\mathrm{cm}^{-1}$ ) of the first- and second-order Raman spectra observed in $\mathrm{ZnO}$ nanorods.

\begin{tabular}{|c|c|c|c|c|c|c|c|c|}
\hline Wave number $\left(\mathrm{cm}^{-1}\right)$ & 333 & 383 & 438 & 582 & 661 & 982 & 1109 & 1140 \\
\hline Process & $E_{2 \mathrm{H}}-E_{2 \mathrm{~L}}$ & $A_{1}(\mathrm{TO})$ & $E_{2 \mathrm{H}}$ & $E_{1}(\mathrm{LO})$ & $\mathrm{TA}+\mathrm{LO}$ & $2 \mathrm{TO}$ & $2 \mathrm{LO}$ & $2 A_{1}(\mathrm{LO}), 2 E_{1}(\mathrm{LO}) ; 2 \mathrm{LO}$ \\
\hline
\end{tabular}

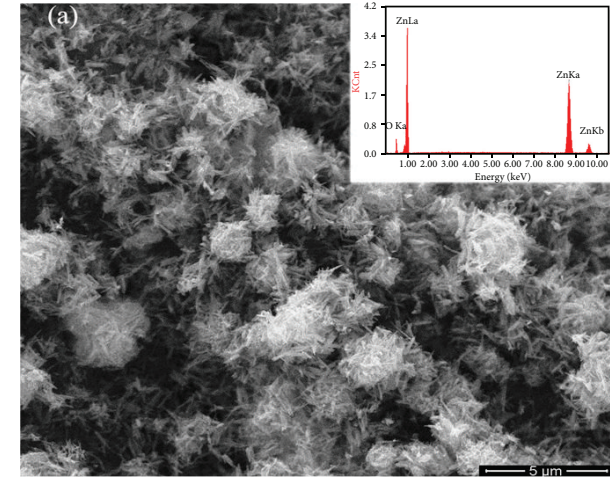

(a)

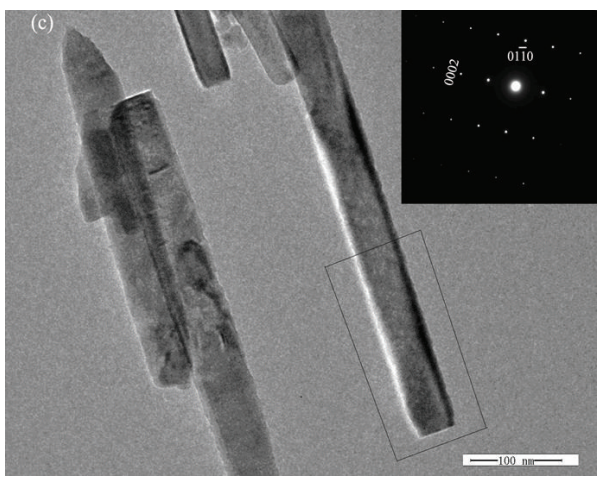

(c)

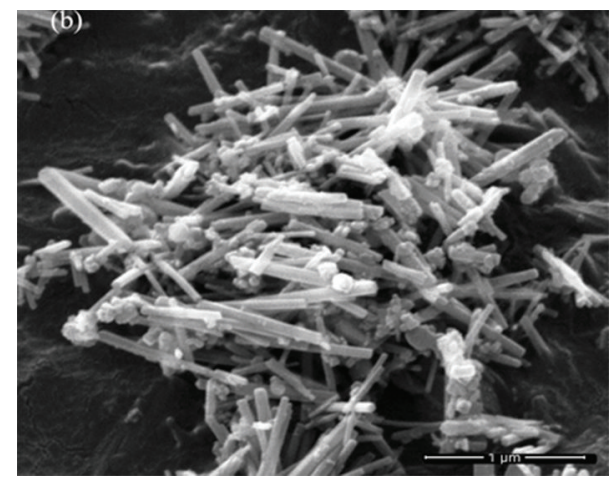

(b)

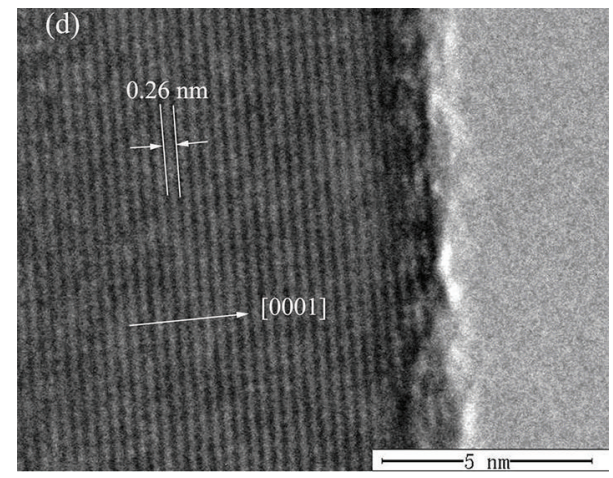

(d)

FIGURE 3: (a) Low magnification SEM image of the as-prepared ZnO nanorods with the corresponding EDS (inset). (b) A representative SEM image of the $\mathrm{ZnO}$ nanorods. (c) A representative TEM image of the $\mathrm{ZnO}$ nanorods with the corresponding SAED pattern (inset). (d) HRTEM image showing the difference between two lattice fringes, which is about $0.26 \mathrm{~nm}$.

Aliquat 336-assisted chemical solution method has wide application in the fabrication of large-scale $\mathrm{ZnO}$ nanocrystals with rod-like shapes. Figure 3(c) shows the TEM image of $\mathrm{ZnO}$ nanorods with sharp tips and smoother surfaces. No amorphous layer was found at the surface of nanorods. The corresponding SAED pattern obtained from the shown nanorods confirmed that the synthesized products have single crystalline structures and grew along the [0001] direction (shown as inset in Figure 3(c)). Figure 3(d) shows the HRTEM image of the marked nanorod. The image clearly reveals that only the fringes of (002) planes with a lattice spacing of about $0.26 \mathrm{~nm}$ can be observed, indicating that the individual $\mathrm{ZnO}$ nanorod is a single crystal. Furthermore, the spacing of $0.26 \mathrm{~nm}$ between two adjacent lattice planes corresponds to the distance between (002) planes indicating that [0001] is the growth direction of the $\mathrm{ZnO}$ nanorods. This is consistent with the XRD inferences. To further confirm the composition of the prepared product, EDS coupled to SEM was recorded. The inset of Figure 3(a) is the EDS from the corresponding SEM, showing that zinc and oxygen are the only detected elements, without any other element contamination. The calculated atomic ratio of $\mathrm{Zn}$ and $\mathrm{O}$ is about $1.15: 1$, likely indicating the presence of oxygen deficiency.

The Raman scattering spectrum of the samples is shown in Figure 4(a), and the frequencies of the Raman active phonon modes are presented in Table 1 . This is consistent with previously reported results about optical phonon modes of $\mathrm{ZnO}$ nanorods, and no impurity relevant Raman peaks appear in the Raman spectrum [32-34]. The Raman active zone-center optical phonons predicted by the group theory are $A_{1}+E_{1}+2 E_{2}$. The phonons of $A_{1}$ and $E_{1}$ symmetry are polar phonons and hence exhibiting different frequencies for the transverse-optical (TO) and longitudinal-optical (LO) phonons. Nonpolar phonon modes with symmetry $E_{2}$ have two frequencies. $E_{2 \mathrm{H}}$ is associated with oxygen atoms and $E_{2 \mathrm{~L}}$ is associated with $\mathrm{Zn}$ sublattice. The presence of sharp $E_{2 \mathrm{H}}\left(438 \mathrm{~cm}^{-1}\right)$ mode with high intensity and the second-order Raman mode at $333 \mathrm{~cm}^{-1}$ in the Raman scattering indicates that the obtained sample possesses the wurtzite hexagonal phase of $\mathrm{ZnO}$ with good crystal quality. 


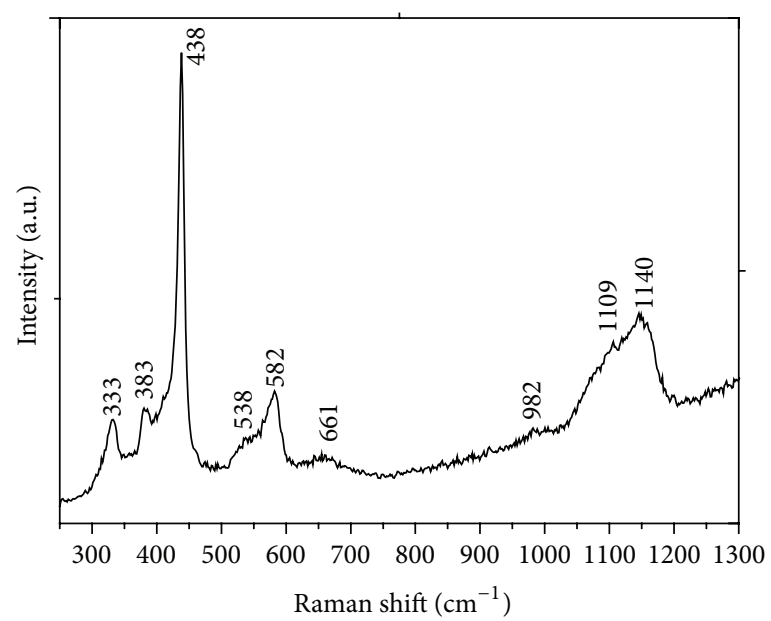

(a)

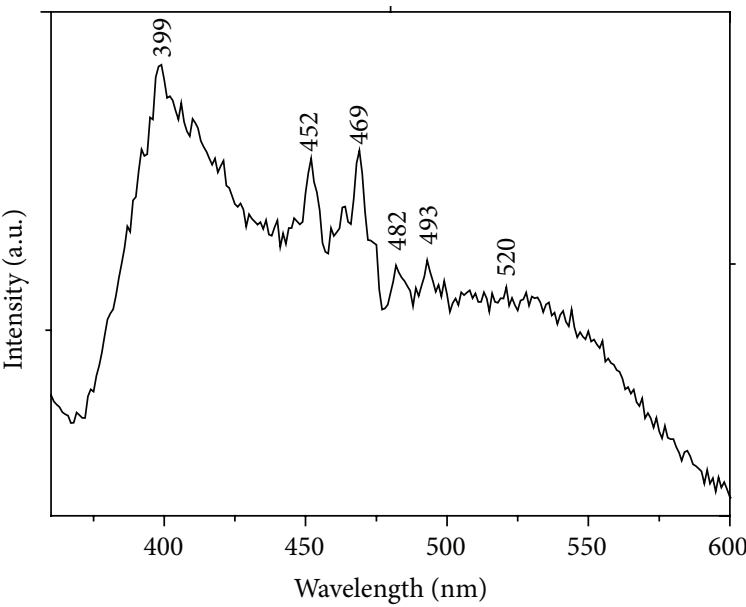

(b)

FIGURE 4: (a) Raman spectrum of the as-prepared $\mathrm{ZnO}$ nanorods with excitation wavelength $514.5 \mathrm{~nm}$. (b) Room temperature PL spectrum of the $\mathrm{ZnO}$ nanorods with excitation wavelength $325 \mathrm{~nm}$.

The $E_{1}(\mathrm{LO})\left(582 \mathrm{~cm}^{-1}\right)$ is associated with lattice defects, such as oxygen vacancy and zinc interstitial [35], which is in accordance with the result provided by EDS. According to the previous research, the acoustic combination of $A_{1}$ and $E_{2}$ was observed around $1101 \mathrm{~cm}^{-1}$ [36]. Our result shows a broad band between 1050 and $1200 \mathrm{~cm}^{-1}$, which confirms before the mentioned report. The broad and weak peaks at $661,982 \mathrm{~cm}^{-1}$ should belong to the multiphonons process [37].

Figure 4(b) shows the room temperature PL spectrum of the $\mathrm{ZnO}$ nanorod samples. The UV emission at $\sim 399 \mathrm{~nm}$ is attributed to the band edge exciton emission [38], and the blue-green emission with PL peaks at 452, 469, 482, and $493 \mathrm{~nm}$ mainly originates from structural defects such as oxygen vacancies which often were detected in the $\mathrm{ZnO}$ nanocrystals prepared by low temperature grown methods [39-42]. In addition, the broad green emission around $520 \mathrm{~nm}$ can be observed. The PL spectral characteristics differ somewhat from those of typical spectra of $\mathrm{ZnO}$ crystals, which usually exhibit a narrow UV absorption peak at 370$390 \mathrm{~nm}$ and a broad green emission at 510-550 nm [38]. The exact mechanisms for the $\mathrm{ZnO}$ visible emission are controversial and not clear so far. However, the visible emission should be related to localized states in the band gap since the photon energy of visible light is far less than the band gap of $\mathrm{ZnO}$. Therefore, it is a widely accepted view that the $\mathrm{ZnO}$ visible emission is due to radial recombination of the photogenerated hole with the electrons that belong to the oxygen vacancies [43-45]. Combined with the previous analysis, the presence of blue-green emission should further confirm that the structural defects such as oxygen vacancies exist in the lattice of the obtained $\mathrm{ZnO}$ nanorods.

\section{Conclusion}

In summary, large-scale $\mathrm{ZnO}$ nanorods with diameters ranging from 20 to $80 \mathrm{~nm}$ and length from $400 \mathrm{~nm}$ to $1.2 \mu \mathrm{m}$ were successfully fabricated using solution chemical route assisted with Aliquat 336 as a soft template. Aliquat 336 can be simply recovered by salts-induced phase separation. A facile and clean synthetic process of $\mathrm{ZnO}$ nanorods was demonstrated. The XRD pattern and SEM and TEM analysis reveal that the $\mathrm{ZnO}$ nanorods have the wurtzite single crystalline structure with uniform morphologies and smooth surfaces, and a preferential growth direction along the $c$-axis. In the Raman spectra, the intense $E_{2}$ modes, which include low- and highfrequency vibrations, approve the wurtzite structure of $\mathrm{ZnO}$ nanorods. The $E_{1}(\mathrm{LO})$ process shows the presence of lattice defects in the $\mathrm{ZnO}$ nanorod crystals. The added appearances of blue-green emission in the PL spectrum further confirm the existence of oxygen vacancies in the $\mathrm{ZnO}$ nanorod lattices.

\section{Conflict of Interests}

The authors declare that they do not have any commercial or associative interest that represents a conflict of interests in connection with the work submitted.

\section{Acknowledgments}

The authors are grateful for the financial support from the Science and Research Foundation of Yunnan University (Grant no. 2010YB045), the financial support from Yunnan Province Education Department (Grant no. 2011Z017), and the samples testing services from the Advanced Analysis and Measurement Center of Yunnan University.

\section{References}

[1] C. F. Klingshirn, "ZnO: material, physics and applications," ChemPhysChem, vol. 8, no. 6, pp. 782-803, 2007.

[2] H. Yan, R. He, J. Pham, and P. Yang, "Morphogenesis of onedimensional $\mathrm{ZnO}$ nano- and microcrystals," Advanced Materials, vol. 15, no. 5, pp. 402-405, 2003. 
[3] Z. L. Wang, "Zinc oxide nanostructures: growth, properties and applications," Journal of Physics Condensed Matter, vol. 16, no. 25, pp. R829-R858, 2004.

[4] G.-C. Yi, C. Wang, and W. I. Park, "ZnO nanorods: synthesis, characterization and applications," Semiconductor Science and Technology, vol. 20, no. 4, pp. S22-S34, 2005.

[5] X. Hou, F. Zhou, and W. Liu, "A facile low-cost synthesis of $\mathrm{ZnO}$ nanorods via a solid-state reaction at low temperature," Materials Letters, vol. 60, no. 29-30, pp. 3786-3788, 2006.

[6] B. Liu and H. C. Zeng, "Hydrothermal synthesis of $\mathrm{ZnO}$ nanorods in the diameter regime of $50 \mathrm{~nm}$," Journal of the American Chemical Society, vol. 125, no. 15, pp. 4430-4431, 2003.

[7] J. Joo, S. G. Kwon, J. H. Yu, and T. Hyeon, "Synthesis of $\mathrm{ZnO}$ nanocrystals with cone, hexagonal cone, and rod shapes via non-hydrolytic ester elimination sol-gel reactions," Advanced Materials, vol. 17, no. 15, pp. 1873-1877, 2005.

[8] D. K. Bhat, "Facile synthesis of $\mathrm{ZnO}$ nanorods by microwave irradiation of zinc-hydrazine hydrate complex," Nanoscale Research Letters, vol. 3, no. 1, pp. 31-35, 2008.

[9] T. Alammar and A.-V. Mudring, "Facile ultrasound-assisted synthesis of $\mathrm{ZnO}$ nanorods in an ionic liquid," Materials Letters, vol. 63, no. 9-10, pp. 732-735, 2009.

[10] L. Xu, Y. Guo, Q. Liao, J. Zhang, and D. Xu, "Morphological control of $\mathrm{ZnO}$ nanostructures by electrodeposition," Journal of Physical Chemistry B, vol. 109, no. 28, pp. 13519-13522, 2005.

[11] W. Yu, X. Li, and X. Gao, "Catalytic synthesis and structural characteristics of high-quality tetrapod-like $\mathrm{ZnO}$ nanocrystals by a modified vapor transport process," Crystal Growth and Design, vol. 5, no. 1, pp. 151-155, 2005.

[12] M. Kashif, U. Hashim, M. E. Ali et al., "Effect of different seed solutions on the morphology and electrooptical properties of ZnO nanorods," Journal of Nanomaterials, vol. 2012, Article ID 452407, 6 pages, 2012.

[13] B. Weintraub, Z. Zhou, Y. Li, and Y. Deng, "Solution synthesis of one-dimensional $\mathrm{ZnO}$ nanomaterials and their applications," Nanoscale, vol. 2, no. 9, pp. 1573-1587, 2010.

[14] B. Liu and H. C. Zeng, "Room temperature solution synthesis of monodispersed single-crystalline $\mathrm{ZnO}$ nanorods and derived hierarchical nanostructures," Langmuir, vol. 20, no. 10, pp. 4196-4204, 2004.

[15] S. M. Reed and J. E. Hutchison, "Green chemistry in the organic teaching laboratory: an environmentally benign synthesis of adipic acid," Journal of Chemical Education, vol. 77, no. 12, pp. 1627-1629, 2000.

[16] A. J. Pezhathinal, K. Rocke, L. Susanto et al., "Colorful chemical demonstrations on the extraction of anionic species from water into ether mediated by tricaprylylmethylammonium chloride (Aliquat 336), a liquid-liquid phase-transfer agent," Journal of Chemical Education, vol. 83, no. 8, pp. 1161-1166, 2006.

[17] P. Giridhar, K. A. Venkatesan, T. G. Srinivasan, and P. R. V. Rao, "Extraction of fission palladium by Aliquat 336 and electrochemical studies on direct recovery from ionic liquid phase," Hydrometallurgy, vol. 81, no. 1, pp. 30-39, 2006.

[18] Y. Yi-Jun, S. Guan-Yong, M. H. W. Lam, P. K. S. Lam, and Y. Hong-Xia, "Cloud point extraction of bisphenol a from water utilizing cationic surfactant aliquat 336," Fenxi Huaxue/Chinese Journal of Analytical Chemistry, vol. 37, no. 12, pp. 1717-1721, 2009.

[19] J.-P. Mikkola, P. Virtanen, and R. Sjöholm, "Aliquat 336-a versatile and affordable cation source for an entirely new family of hydrophobic ionic liquids," Green Chemistry, vol. 8, no. 3, pp. 250-255, 2006.
[20] D. Kogelnig, A. Stojanovic, M. Galanski et al., "Greener synthesis of new ammonium ionic liquids and their potential as extracting agents," Tetrahedron Letters, vol. 49, no. 17, pp. 27822785, 2008.

[21] B. K.-W. Man, M. H.-W. Lam, P. K. S. Lam, R. S. S. Wu, and G. Shaw, "Cloud-point extraction and preconcentration of cyanobacterial toxins (microcystins) from natural waters using a cationic surfactant," Environmental Science and Technology, vol. 36, no. 18, pp. 3985-3990, 2002.

[22] M. Antonietti, D. Kuang, B. Smarsly, and Y. Zhou, "Ionic liquids for the convenient synthesis of functional nanoparticles and other inorganic nanostructures," Angewandte Chemie, vol. 43, no. 38, pp. 4988-4992, 2004.

[23] Z. Li, Z. Jia, Y. Luan, and T. Mu, "Ionic liquids for synthesis of inorganic nanomaterials," Current Opinion in Solid State and Materials Science, vol. 12, no. 1, pp. 1-8, 2008.

[24] L. Wang, L. Chang, B. Zhao, Z. Yuan, G. Shao, and W. Zheng, "Systematic investigation on morphologies, forming mechanism, photocatalytic and photoluminescent properties of $\mathrm{ZnO}$ nanostructures constructed in ionic liquids," Inorganic Chemistry, vol. 47, no. 5, pp. 1443-1452, 2008.

[25] L. Wang, L.-X. Chang, L.-Q. Wei, S.-Z. Xu, M.-H. Zeng, and S.-L. Pan, "The effect of $1-\mathrm{N}$-alkyl chain of ionic liquids $\left[\mathrm{C}_{n} \mathrm{mim}\right]^{+} \mathrm{Br}^{-}(n=2,4,6,8)$ on the aspect ratio of $\mathrm{ZnO}$ nanorods: syntheses, morphology, forming mechanism, photoluminescence and recyclable photocatalytic activity," Journal of Materials Chemistry, vol. 21, no. 39, pp. 15732-15740, 2011.

[26] Z. Li, Y. Luan, Q. Wang et al., "ZnO nanostructure construction on zinc foil: the concept from an ionic liquid precursor aqueous solution," Chemical Communications, no. 41, pp. 6273-6275, 2009.

[27] J. Q. Hu, Q. Li, N. B. Wong, C. S. Lee, and S. T. Lee, "Synthesis of uniform hexagonal prismatic $\mathrm{ZnO}$ whiskers," Chemistry of Materials, vol. 14, no. 3, pp. 1216-1219, 2002.

[28] L. Vayssieres, K. Keis, A. Hagfeldt, and S.-E. Lindquist, “Threedimensional array of highly oriented crystalline $\mathrm{ZnO}$ microtubes," Chemistry of Materials, vol. 13, no. 12, pp. 4395-4398, 2001.

[29] P. Rai, S. K. Tripathy, N.-H. Park, K.-J. O, I.-H. Lee, and Y.-T. Yu, "Synthesis of violet light emitting single crystalline $\mathrm{ZnO}$ nanorods by using CTAB-assisted hydrothermal method," Journal of Materials Science, vol. 20, no. 10, pp. 967-971, 2009.

[30] X. M. Sun, X. Chen, Z. X. Deng, and Y. D. Li, "A CTAB-assisted hydrothermal orientation growth of $\mathrm{ZnO}$ nanorods," Materials Chemistry and Physics, vol. 78, no. 1, pp. 99-104, 2003.

[31] H.-J. Zhai, W.-H. Wu, F. Lu, H.-S. Wang, and C. Wang, "Effects of ammonia and cetyltrimethylammonium bromide (CTAB) on morphologies of $\mathrm{ZnO}$ nano- and micromaterials under solvothermal process," Materials Chemistry and Physics, vol. 112, no. 3, pp. 1024-1028, 2008.

[32] A.-J. Cheng, Y. Tzeng, H. Xu et al., "Raman analysis of longitudinal optical phonon-plasmon coupled modes of aligned $\mathrm{ZnO}$ nanorods," Journal of Applied Physics, vol. 105, Article ID 073104, 7 pages, 2009.

[33] G. W. Cong, H. Y. Wei, P. F. Zhang et al., "One-step growth of $\mathrm{ZnO}$ from film to vertically well-aligned nanorods and the morphology-dependent Raman scattering," Applied Physics Letters, vol. 87, Article ID 231903, 3 pages, 2005.

[34] R. Zhang, P.-G. Yin, N. Wang, and L. Guo, "Photoluminescence and Raman scattering of $\mathrm{ZnO}$ nanorods," Solid State Sciences, vol. 11, no. 4, pp. 865-869, 2009. 
[35] S. J. Chen, Y. C. Liu, Y. M. Lu, J. Y. Zhang, D. Z. Shen, and $\mathrm{X}$. W. Fan, "Photoluminescence and Raman behaviors of $\mathrm{ZnO}$ nanostructures with different morphologies," Journal of Crystal Growth, vol. 289, no. 1, pp. 55-58, 2006.

[36] R. P. Wang, G. Xu, and P. Jin, "Size dependence of electronphonon coupling in $\mathrm{ZnO}$ nanowires," Physical Review B, vol. 69, no. 11, Article ID 113303, 3 pages, 2004.

[37] R. Cuscó, E. Alarcón-Lladó, J. Ibáñez et al., “Temperature dependence of Raman scattering in ZnO," Physical Review B, vol. 75, no. 16, Article ID 165202, 12 pages, 2007.

[38] V. A. Fonoberov, K. A. Alim, A. A. Balandin, F. Xiu, and J. Liu, "Photoluminescence investigation of the carrier recombination processes in $\mathrm{ZnO}$ quantum dots and nanocrystals," Physical Review B, vol. 73, Article ID 165317, 9 pages, 2006.

[39] J. A. Prybyla, S. P. Riege, S. P. Grabowski, and A. W. Hunt, “Temperature dependence of electromigration dynamics in $\mathrm{Al}$ interconnects by real-time microscopy," Applied Physics Letters, vol. 73, no. 8, pp. 1083-1085, 1998.

[40] H.-M. Xiong, Y. Xu, Q.-G. Ren, and Y.-Y. Xia, "Stable aqueous ZnO@polymer core-shell nanoparticles with tunable photoluminescence and their application in cell imaging," Journal of the American Chemical Society, vol. 130, no. 24, pp. 7522-7523, 2008.

[41] Z. Li, Y. Fang, L. Peng, D. Pan, and M. Wu, "EDTA-assisted synthesis of rose-like $\mathrm{ZnO}$ architectures," Crystal Research and Technology, vol. 45, no. 10, pp. 1083-1086, 2010.

[42] A. S. Reddy, Y.-H. Kuo, S. B. Atla et al., "Low-temperature synthesis of rose-like $\mathrm{ZnO}$ nanostructures using surfactin and their photocatalytic activity," Journal of Nanoscience and Nanotechnology, vol. 11, no. 6, pp. 5034-5041, 2011.

[43] H.-M. Xiong, "Photoluminescent $\mathrm{ZnO}$ nanoparticles modified by polymers," Journal of Materials Chemistry, vol. 20, no. 21, pp. 4251-4262, 2010.

[44] K. Vanheusden, W. L. Warren, C. H. Seager, D. R. Tallant, J. A. Voigt, and B. E. Gnade, "Mechanisms behind green photoluminescence in $\mathrm{ZnO}$ phosphor powders," Journal of Applied Physics, vol. 79, Article ID 362349, 8 pages, 1996.

[45] P. Rai, J.-N. Jo, I.-H. Lee, and Y.-T. Yu, "Fabrication of flower-like $\mathrm{ZnO}$ microstructures from $\mathrm{ZnO}$ nanorods and their photoluminescence properties," Materials Chemistry and Physics, vol. 124, no. 1, pp. 406-412, 2010. 

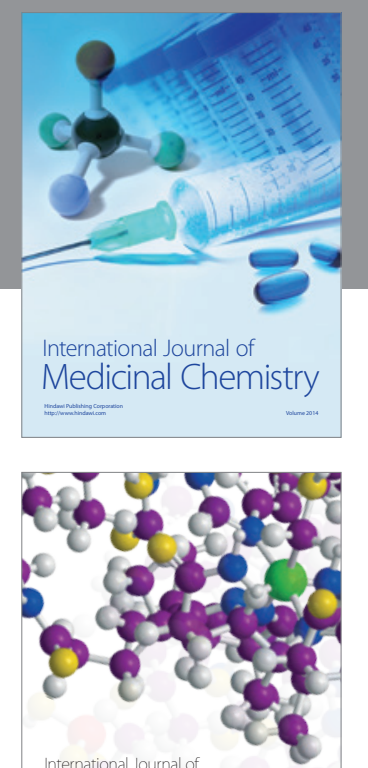

\section{Carbohydrate} Chemistry

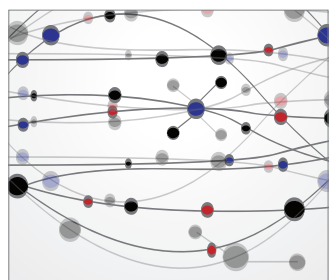

The Scientific World Journal
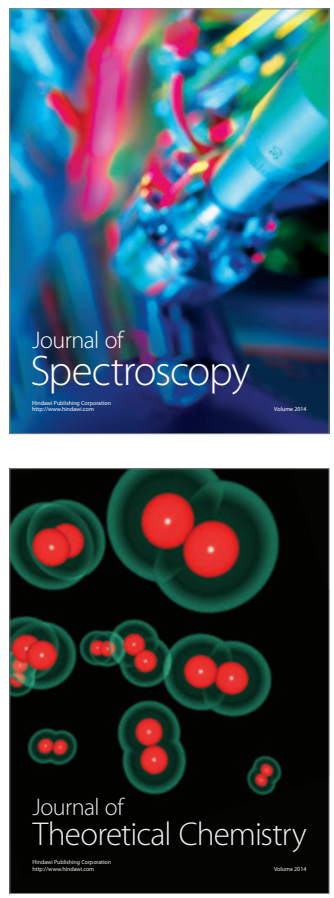
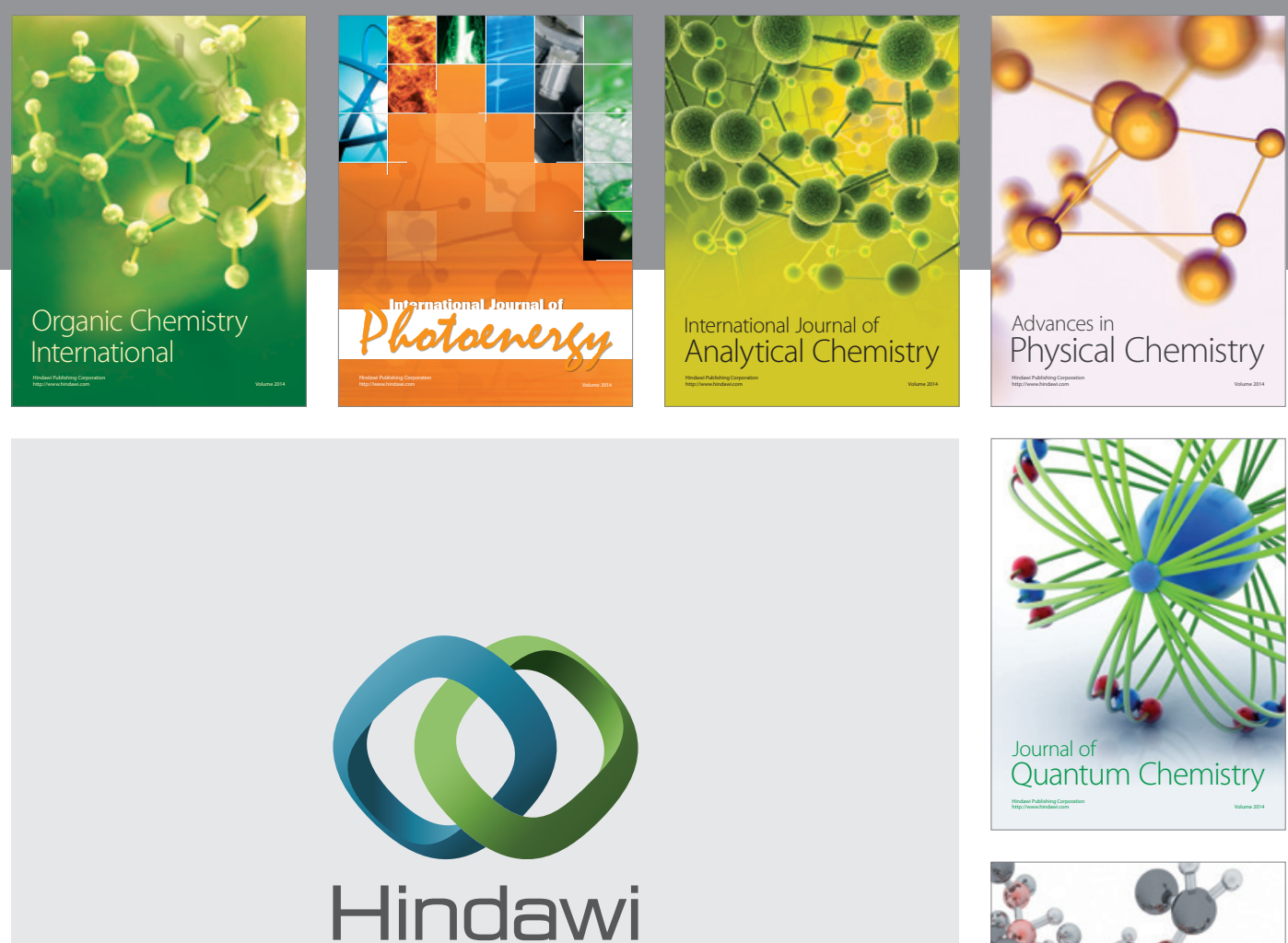

Submit your manuscripts at

http://www.hindawi.com

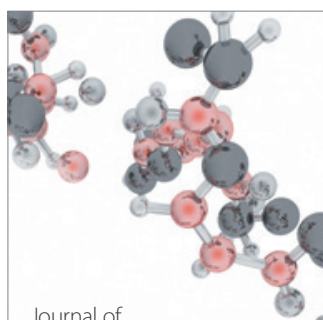

Analytical Methods

in Chemistry

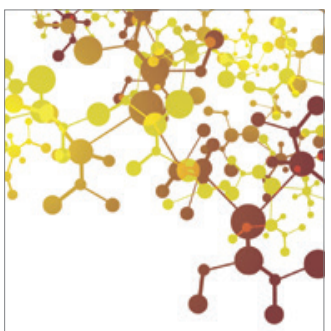

Journal of

Applied Chemistry

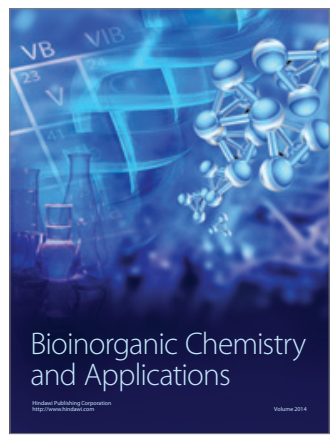

Inorganic Chemistry
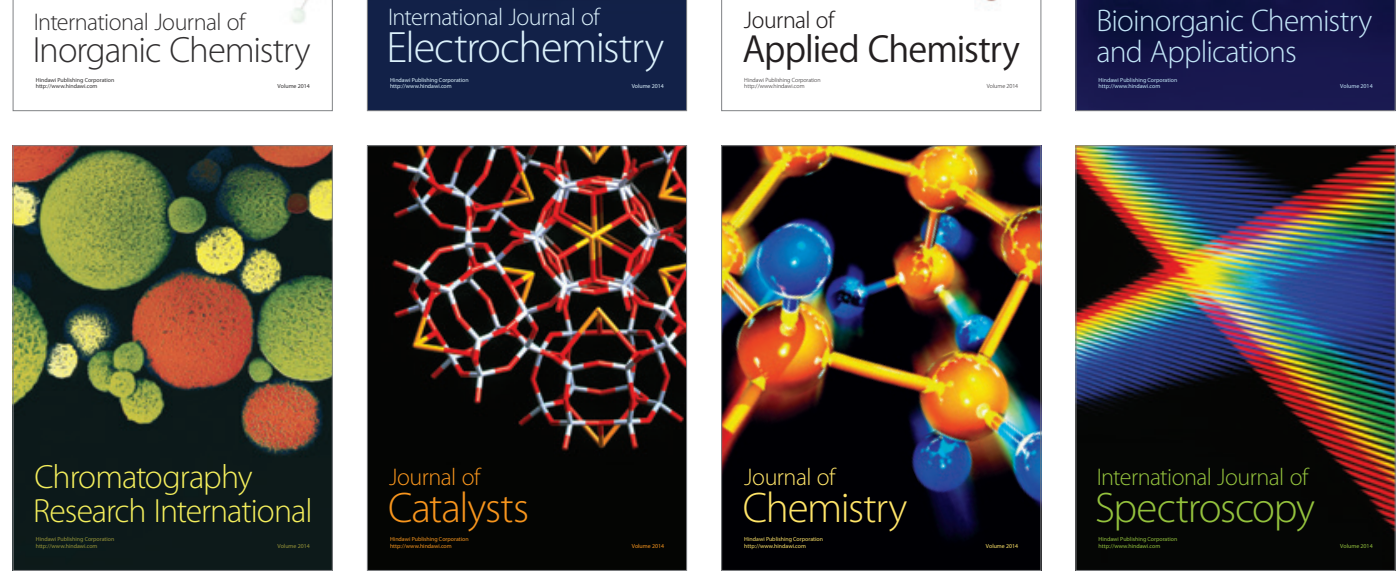